\title{
Studies on the Histopathology of Temporal Arteritis
}

\author{
Angeline L. Wang ${ }^{a}$ Meisha L. Raven ${ }^{a, b}$ Krishna Surapaneni ${ }^{a, b}$ \\ Daniel M. Albert ${ }^{a, b}$ \\ ${ }^{a}$ Department of Ophthalmology and Visual Sciences, University of Wisconsin, and ${ }^{\mathrm{b}}$ McPherson Eye Research \\ Institute, Madison, Wis., USA
}

\section{Key Words}

Temporal arteritis · Giant cell arteritis · Granulomatous inflammation $\cdot$ CD68 $\cdot$ Vasculitis

\begin{abstract}
Aims: The aim of this paper was to identify the location and to grade the severity of most significant inflammation within positive temporal artery biopsies along with other key clinical and histologic characteristics. Methods: Charts and pathology slides for 70 patients diagnosed with temporal arteritis at the University of Wisconsin (UW) Hospital and Clinics from 1989 to 2015 were reviewed. A subset of 48 specimens was immunostained for CD68 and graded on a scale from 0 to +++ ; the location of staining was recorded. Results: The most severe granulomatous inflammation was in the media and adventitia in 13\% (9/70) of the biopsies; the remaining had uniform full thickness inflammation. Of the slides that were stained with CD68, 94\% (45/48) were positive. In 42\% (19/45), the stained cells were found mainly in the muscularis and adventitia. Seven percent (3/45) of the slides had staining solely around the internal elastic lamina, and $2 \%$ (1/45) had staining limited to the intima. Conclusions: With a few exceptions, granulomatous inflammation in positive temporal artery biopsies is most evident at the media and adventitia or is uniform throughout the layers of the artery.
\end{abstract}

๑) 2016 S. Karger AG, Basel

\section{KARGER
E-Mail karger@karger.com
www.karger.com/oop \\ KARGER
E-Mail karger@karger.com
www.karger.com/oop}

Our study lends support to the theory that the muscularis and adventitia may play an inciting role in the pathogenesis of temporal arteritis.

(c) 2016 S. Karger AG, Basel

\section{Introduction}

Temporal arteritis is an inflammatory vasculitis that is considered an ophthalmic emergency. It is the most common form of systemic vasculitis affecting the elderly and can lead to rapidly progressive and permanent vision loss. Prompt diagnosis and treatment with systemic corticosteroids is required to prevent vision loss [1]. Clinical manifestations of temporal arteritis include headache, visual changes, jaw claudication, scalp tenderness, polymyalgia rheumatica, and fatigue [2]. Laboratory testing frequently reveals elevated inflammatory markers, including elevated erythrocyte sedimentation rate (ESR), and C-reactive protein (CRP).

The 'gold standard' for diagnosis is the temporal artery biopsy [3]. The current literature describes a positive biopsy as revealing chronic granulomatous inflammation - consisting of epithelioid histiocytes, multinucleated giant cells, T lymphocytes, and macrophages - concentrated at the level of the internal elastic lamina [4-6]. 
Intimal hyperplasia and fragmentation of the internal elastic lamina are also frequently seen on histopathology. Recently, CD68 immunostaining for the presence of macrophages has been shown to be useful in differentiating between indeterminate and positive temporal artery biopsy specimens [7].

The internal elastic lamina is frequently assumed to be the initial and possible inciting site of temporal arteritis based on (1) the accumulation of giant cells and histiocytes along the zone of the previous elastic lamina; (2) elastic fragments found with the giant cells, and (3) the lack of involvement of arteries lacking an internal elastic lamina (e.g. the intracranial arteries) $[4,8,9]$. Other experimental data suggests that the disease is initiated in the outer layer of the arterial wall, with inflammatory cells entering through the vasa vasorum and subsequently infiltrating into all layers of the artery wall [10].

The purpose of this study is to verify the location and severity of granulomatous inflammation in positive temporal arteries along with other clinical and histologic characteristics and to compare these findings to previous reports.

\section{Methods}

\section{Patients and Specimens}

The list of patients with biopsy-proven temporal arteritis was generated by searching the University of Wisconsin (UW) Eye Pathology Laboratory and UW Surgical Pathology Laboratory databases for the terms 'giant cell arteritis' and 'temporal arteritis.' Charts for patients with positive temporal artery biopsies from a 25-year period, 1989-2014, were reviewed for demographic information, clinical signs and symptoms, laboratory results, and treatment course. Cases with indeterminate diagnoses were excluded, as were cases where clinical information was unavailable. A total of 70 patients were included in the study.

The upper limit of normal for ESR was determined by the formula proposed by Miller et al. [11] in 1983: age/2 in men and (age $+10) / 2$ in women. Elevated CRP was defined as $\geq 2$, and elevated platelets were defined as $\geq 450$.

All biopsies were submitted in $10 \%$ formalin. Upon grossing, the tissues were examined for length and color, then subsequently cut into $2-\mathrm{mm}$ pieces and routinely processed. They were then embedded on end and serially sectioned in $25-\mu \mathrm{m}$ intervals with a thickness of $5 \mu \mathrm{m}$. Initially, $>50 \%$ of the paraffin block was sectioned. If the pathologist saw no granulomatous inflammation in the initial examination, then $>90 \%$ of the paraffin block was sectioned.

All temporal artery biopsy slides for the 70 patients, including $\mathrm{H} \& \mathrm{E}$ and PAS stained slides, were reviewed for the presence of intimal hyperplasia, lumen occlusion, breaks of the internal elastic lamina, skip lesions, and inflammatory cells, and the location of most severe inflammation was also determined by a trained ocular pathologist.

Temporal Arteritis
Table 1. Patient clinical and demographic information

\begin{tabular}{|c|c|}
\hline \multicolumn{2}{|l|}{ Demographics } \\
\hline Male & $20 / 70$ \\
\hline Female & $50 / 70$ \\
\hline Mean age (range) & $74.5(52-94)$ \\
\hline \multicolumn{2}{|l|}{ Laboratory results } \\
\hline Elevated ESR & $55 / 69$ \\
\hline Mean positive ESR (range) & $61.8(46-130)$ \\
\hline Mean negative ESR (range) & $28.6(16-44)$ \\
\hline Elevated CRP & $32 / 38$ \\
\hline Double negative ESR and CRP & $6 / 38$ \\
\hline Elevated platelets & $8 / 35$ \\
\hline \multicolumn{2}{|l|}{ Presenting symptoms } \\
\hline Headache & $46 / 70$ \\
\hline Jaw claudication & $44 / 70$ \\
\hline Fatigue & $26 / 70$ \\
\hline Vision loss & $26 / 70$ \\
\hline Bilateral & 7/26 (14 eyes) \\
\hline Unilateral & $19 / 26$ ( 19 eyes) \\
\hline Persistent & $17 / 26$ ( 21 eyes $)$ \\
\hline Eyes with $<20 / 200$ visual acuity & $14 / 21$ \\
\hline Scalp tenderness & $24 / 70$ \\
\hline Proximal myalgia & $23 / 70$ \\
\hline Weight loss & $18 / 70$ \\
\hline Fevers & $12 / 70$ \\
\hline Anorexia & $11 / 70$ \\
\hline Diplopia & $7 / 70$ \\
\hline Night sweats & $4 / 70$ \\
\hline \multicolumn{2}{|l|}{ Ophthalmologic examination findings } \\
\hline Optic disc edema or pallor & $19 / 59$ \\
\hline Afferent pupillary defect & $14 / 57$ \\
\hline Retinal artery occlusion & $9 / 59$ \\
\hline Sixth nerve palsy & $3 / 59$ \\
\hline Scleritis or uveitis & $2 / 59$ \\
\hline
\end{tabular}

\section{Immunohistochemistry}

A subset of 48 patient specimens was immunostained for CD68. Deparaffinization of all slides was done by placing the slides in a $58^{\circ} \mathrm{C}$ oven for $10 \mathrm{~min}$. They were rehydrated in a stepwise fashion in alcohols of decreasing concentration and then washed in deionized water. The slides were placed in 3\% hydrogen peroxide for $10 \mathrm{~min}$ and washed several times in deionized water.

Antigen retrieval was performed by placing the slides in Coplin jars with $1 \mathrm{~mm}$ ethylenediaminetetraacetic acid at a $\mathrm{pH}$ of 8.0 in a $95^{\circ} \mathrm{C}$ water bath for $20 \mathrm{~min}$. The Coplin jars were removed from the water bath and allowed to sit for 20 min before being in a jar of tap water for $10 \mathrm{~min}$. The sections were washed 2 times in deionized water and then incubated with primary antibody (monoclonal mouse anti-human CD68; Innovex Biosciences, Richmond, Calif., USA) for $1 \mathrm{~h}$ at room temperature in a humidified chamber. The slides were washed for $1.5 \mathrm{~min}$ in phosphate-buffered saline (PBS) and then incubated with secondary linking antibody (Innovex Biosciences) for $10 \mathrm{~min}$ in a humidified chamber.

Next, the slides were washed with PBS and incubated with horseradish peroxidase label for $10 \mathrm{~min}$ in a humidified chamber. 
Fig. 1. Histopathology of temporal artery biopsy specimens with H\&E staining. a Negative temporal artery biopsy. b Negative temporal artery biopsy with calcific changes. c Positive temporal artery biopsy with granulomatous inflammation centered at the media and adventitia. d Positive temporal artery biopsy with full thickness granulomatous inflammation.

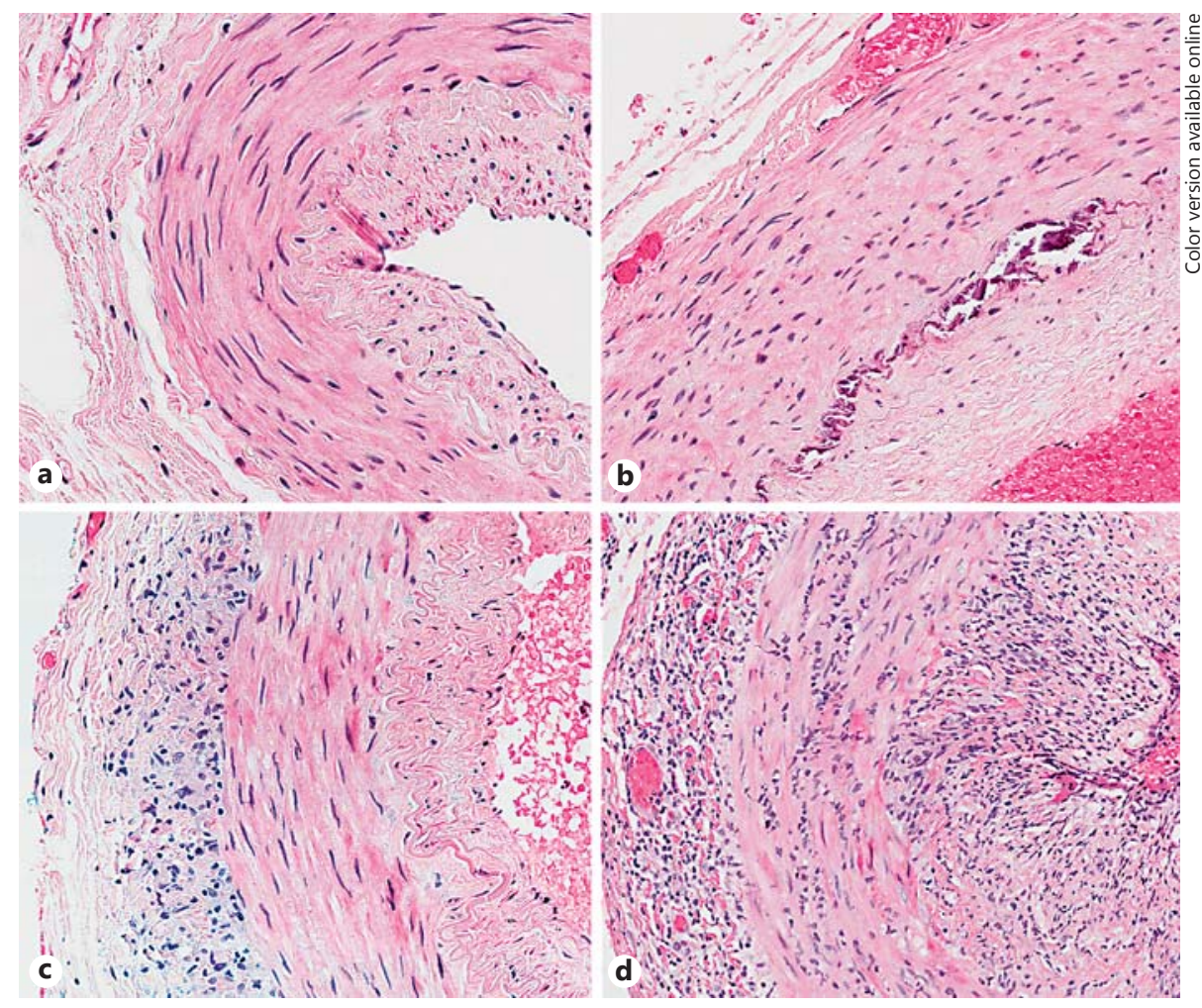

The slides were again washed with PBS and incubated with DAB (3,3'-diaminobenzidine)/substrate solution for $8 \mathrm{~min}$. Deionized water was used to rinse the sections several times to stop any DAB reaction. Gill's II hematoxylin was used to counterstain the tissue for $2 \mathrm{~min}$; the sections were then rinsed in deionized water. Saturated lithium carbonate solution (1.4\% in water) was utilized for bluing the sections for $1 \mathrm{~min}$. The sections were run for several minutes in tap water prior to being dehydrated in alcohols of increasing concentration followed by xylene and then cover slipping.

The staining was graded based on the scale established by Zhou et al. [7], which includes the following: 0 (no staining), + (up to one third of the circumference of $\geq 1$ layer containing cells that stain), ++ (up to two thirds of the circumference of $\geq 1$ layer containing cells that stain), and +++ (the complete circumference of $\geq 1$ layer containing cells that stain).

\section{Results}

Of the 70 total patients, 11 were evaluated by internists prior to biopsy and did not have ophthalmologic examinations done. All other patients were evaluated by an ophthalmologist. The average age of diagnosis for temporal arteritis was 74.5 years, with $71 \%$ (50/70) of positive cases diagnosed in women. Clinical and demographic data are summarized in table 1.
Patients were treated with high-dose systemic steroids for an average of 3.2 days prior to biopsy. Unilateral temporal artery biopsies were submitted in $81 \%$ (57/70) of the cases; the remaining biopsies were bilateral. The mean artery sample length was $19.6 \mathrm{~mm}$.

Histopathologic features of the positive biopsies included lymphocytes (70/70), epithelioid cells (70/70), intimal hyperplasia (69/70), giant cells (57/70), fragmented internal elastic lamina (66/70), lumen narrowing (34/70), and concomitant calcific changes (24/70). Skip areas were noted in $12 \%(8 / 68)$ of the cases. The most severe granulomatous inflammation was located in the media and adventitia in $13 \%$ (9/70) of the biopsies; the remaining specimens had full thickness inflammation. On H\&E stained slides, no biopsies had inflammation isolated at or centered on the internal elastic lamina. Figure 1 illustrates the histopathological grading of the temporal artery specimens.

Of the slides that were stained with CD68, 94\% (45/48) were positive; $40 \%(18 / 45)$ were graded as,$+ 22 \%(10 / 45)$ were graded as ++ , and $38 \%(17 / 45)$ were graded as +++ (fig. 2, table 2). In $49 \%$ (22/45) of the positive samples, the macrophage lysosomal CD68 staining-positive cells were found to be in all three layers of the artery. In $42 \%(19 / 45)$, the stained cells were found mainly in the muscularis and 
Fig. 2. CD68 immunohistochemistry staining and grading of temporal artery biopsy specimens. a CD68 with no staining of histiocytes. $\mathbf{b}+$ staining (up to one third of the circumference of $\geq 1$ layer). $\mathbf{c}++$ staining (up to two thirds of the circumference of $\geq 1$ layer). $\mathbf{d}+++$ staining (the complete circumference of $\geq 1$ layer).
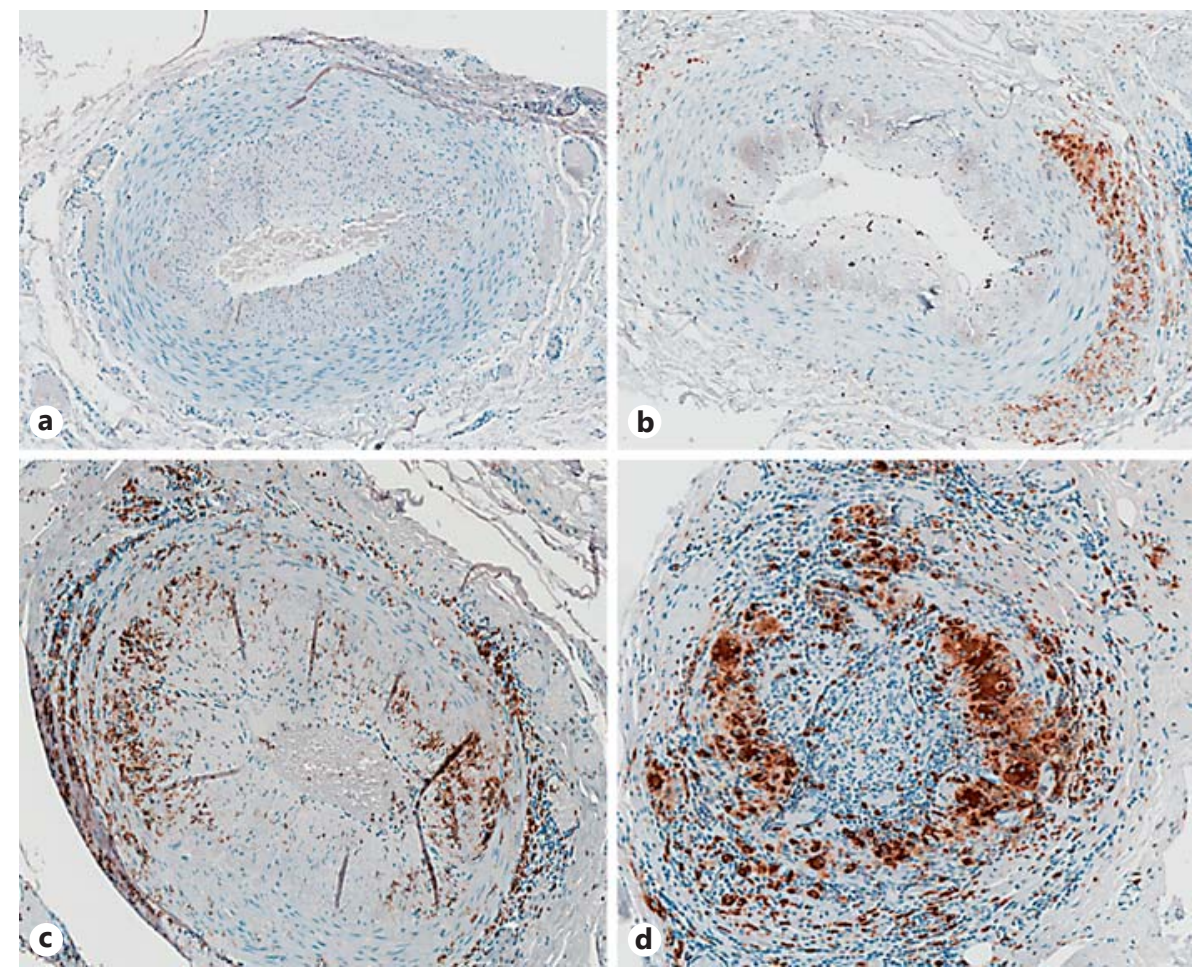

Table 2. Distribution of inflammation with the temporal arteritis biopsy specimens

\begin{tabular}{lrr}
\hline & H\&E & CD68 \\
\hline Intima only & $0 / 70$ & $1 / 45$ \\
Intima and media only & $0 / 70$ & $3 / 45$ \\
Media only & $0 / 70$ & $1 / 45$ \\
Media and adventitia only & $8 / 70$ & $11 / 45$ \\
Adventitia only & $1 / 70$ & $7 / 45$ \\
Full thickness & $61 / 70$ & $22 / 45$ \\
\hline
\end{tabular}

adventitia. Seven percent (3/45) of the slides had staining solely around the internal elastic lamina, and 2\% (1/45) had staining limited to the intima. Six percent $(3 / 48)$ were negative for CD68 staining; all 3 had been stored with their blocks for more than 15 years.

\section{Discussion}

The clinical and laboratory findings in our patients are generally consistent with previous reported series [1]. The most common presenting symptom was head- ache in $66 \%$. Approximately $24 \%$ of the patients presented with permanent vision loss, the most common cause of which was arteritic anterior ischemic optic neuropathy in $76 \%$. Two of the 70 patients (3\%) had no systemic symptoms; in the literature, silent or occult presentations of temporal arteritis constitute up to $20 \%$ of all cases $[12,13]$.

A low or normal ESR has been reported in 5-34\% of the patients with biopsy-proven temporal arteritis [1417]. In our cohort, $20 \%$ of the patients had a normal ESR based on the formula by Miller et al. [11] for calculating the upper limit of normal. About half the patients in our series with a normal ESR also had a normal CRP.

Other studies have suggested that a lower threshold for ESR should be used in the diagnosis of temporal arteritis. A population study of 3,910 healthy Norwegian adults found that the upper reference levels expected to be exceeded by chance $5 \%$ of the time were $19 \mathrm{~mm} \mathrm{~h}^{-1}$ for men and $23 \mathrm{~mm} \mathrm{~h}^{-1}$ for women over the age of 90 years [18]. Using that criterion, all but 1 patient in our series would have had an elevated ESR.

The 'classic' description of a positive temporal artery biopsy has been described as granulomatous inflammation in all layers, primarily centered at the internal elastic lamina, accompanied by intimal hyperplasia and breaks 
in the internal elastic lamina [4-6]. The internal elastic lamina has been suggested as a possible target of the inflammatory reaction [1].

Other experimental data suggest that temporal arteritis is initiated in the outer layer of the arterial wall, with $\mathrm{CD} 4 \mathrm{~T}$ cells entering the artery wall through the vasa vasorum and subsequently orchestrating macrophage differentiation [10]. The inflammatory cells then infiltrate into all layers of the artery wall, leading to myofibroblast proliferation, luminal stenosis, and tissue ischemia. The gatekeepers of the vasculitic process are thought to be toll-like receptors located on dendritic cells at the adventitia-media junction [10]. T-cells with signs of recent activation have been found in the adventitia of the artery wall [19], and macrophages in the adventitia resemble highly activated macrophages that circulate in the blood of temporal arteritis patients, producing interleukin-6 [20].

Our findings support the theory that the muscularis and/or adventitia play an inciting role in the pathogenesis of temporal arteritis. In our study, biopsies of patients with temporal arteritis reveal that the principal focus of chronic granulomatous inflammation is at the level of the media and adventitia. CD68 staining, which has been shown to be a reliable immunohistochemical stain for identifying epithelioid histiocytes [7], confirmed that inflammatory cells were centered around the muscularis and adventitia rather than the internal elastic lamina. A previous immunohistochemical study has likewise shown that inflammatory cells and other inflammatory markers, including interleukin-2, are concentrated at the border between the media and adventitia [21].

Our results are not consistent with a recent study reporting that the most common pattern of inflammation after full thickness inflammation was a concentric bilayer pattern with infiltration of the adventitia and intima with preservation of the media [22].

\section{Conclusions}

Biopsies of patients with temporal arteritis reveal that the principal focus of chronic granulomatous inflammation is at the level of the media and adventitia. Our findings are consistent with previous experimental data that suggest that the disease originates with activation of inflammatory cells in the outer layer of the arterial wall. We hypothesize that the muscularis and adventitia may play an inciting role in the pathogenesis of temporal arteritis.

\section{Acknowledgments}

Funding for this research was provided by NIH Core Grant P30 EY016665 and an Unrestricted Grant from Research to Prevent Blindness, Inc.

\section{Statement of Ethics}

The study protocol was approved by the university's institutional review board. An informed consent waiver was also approved by the institutional review board, as this was a retrospective study.

\section{Disclosure Statement}

None of the authors have any propriety interests, financial completing interests, or conflicts of interest related to this submission.

\section{References}

1 Rahman W, Rahman FZ: Giant cell (temporal) arteritis: an overview and update. Surv Ophthalmol 2005;50:415-428.

2 Hayreh SS, Podhajsky PA, Zimmerman B: Ocular manifestations of giant cell arteritis. Am J Ophthalmol 1998;125:509-520.

3 Nordborg E, Nordborg C: Giant cell arteritis: strategies in diagnosis and treatment. Curr Opin Rheumatol 2004;16:25-30.

4 Albert DM, Searl SS, Craft JL: Histologic and ultrastructural characteristics of temporal arteritis. Ophthalmology 1982;89:1111-1126.

5 Harrison CV: Giant-cell or temporal arteritis: a review. J Clin Path 1948;1:197-211.
6 Cogan DG: Vasculitis: Ophthalmic Manifestations of Systemic Vascular Disease. Philadelphia, W.B. Saunders Co., 1908, pp. 132134.

7 Zhou L, Luneau K, Weyand CM, Biousse V, Newman NJ, Grossniklaus HE: Clinicopathologic correlations in giant cell arteritis: a retrospective study of 107 cases. Ophthalmol 2009;116:1574-1580.

8 Wilkinson IM, Russell RW: Arteries of the head and neck in giant cell arteritis. Arch Neurol 1972;27:378-391.

9 Weyand CM, Bartley GB: Giant cell arteritis: new concepts in pathogenesis and implications for management. Am J Ophthalmol1997;123:392-395.
10 Ma-Krupa W, Kwan M, Goronzy JJ, Weyand CM: Toll-like receptors in giant cell arteritis. Clin Immunol 2005;115:38-46.

11 Miller A, Green M, Robinson D: Simple rule for calculating normal erythrocyte sedimentation rate. Br Med J (Clin Res Ed) 1983;286: 266.

12 Hayreh SS, Podhajsky PA, Zimmerman B: Occult giant cell arteritis: ocular manifestations. Am J Ophthalmol 1998;125:521-526.

13 Healey LA, Wilske KR: Presentation of occult giant cell arteritis. Arthritis Rheum 1980;23: 641-643. 
14 De Lott LB, Burke JF: Use of laboratory markers in deciding whether to perform temporal artery biopsy. JAMA Ophthalmol 2015;133: 605-606.

15 Kermani TA, Schmidt J, Crowson CS, Ytterberg SR, Hunder GG, Matteson EL, Warrington KJ: Utility of erythrocyte sedimentation rate and C-reactive protein for the diagnosis of giant cell arteritis. Semin Arthritis Rheum 2012;41:866-871.

16 Martínez-Taboada VM, Blanco R, Armona J, Uriarte E, Figueroa M, Gonzalez-Gay MA, Rodriguez-Valverde V: Giant cell arteritis with an erythrocyte sedimentation rate lower than 50. Clin Rheumatol 2000;19:73-75.
17 Salvarani C, Hunder GG: Giant cell arteritis with low erythrocyte sedimentation rate: frequency of occurrence in a population-based study. Arthritis Rheum 2001;45:140-145.

18 Wetteland P, Roger M, Solberg HE, Iverson IH: Population-based erythrocyte sedimentation rates in 3,910 subjectively healthy Norwegian adults. A statistical study based on men and women from the Oslo area. J Int Med 1996;240:125-131.

19 Martínez-Taboada V, Hunder NN, Hunder GG, Weyand CM, Goronzy JJ: Recognition of tissue residing antigen by $T$ cells in vasculitic lesions of giant cell arteritis. J Mol Med 1996; 74:695-703.
20 Roche NE, Fulbright JW, Wagner AD, Hunder GC, Goronzy JJ, Weyand CM: Correlation on interleukin- 6 production and disease activity in polymyalgia rheumatica and giant cell arteritis. Arthritis Rheum 1993;36:12861294.

21 Nordborg E, Nordborg C: The inflammatory reaction in giant cell arteritis: an immunohistochemical investigation. Clin Exp Rheumatol 1998;16:165-168.

22 Hernández-Rodríguez J, Murgia G, Villar I, Campo E, Mackie SL, Chakrabarty A, Hensor EM, Morgan AW, Font C, Prieto-González S, Espígol-Frigolé G, Grau JM, Cid MC: Description and validation of histological patterns and proposal of a dynamic model of inflammatory infiltration in giant-cell arteritis. Medicine (Baltimore) 2016;95:1-12. 